\title{
Laboratory Evaluation of Extract from Peels and Seeds of Some Citrus Species against Anopheles Mosquitoes (Diptera: Culicidae)
}

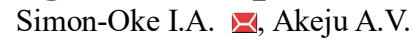

Department of Biology, Federal University of Technology, Akure, Ondo State, Nigeria

$\downarrow$ Corresponding author email: adepejuolayemi@yahoo.com

Journal of Mosquito Research, 2019, Vol.9, No.1 doi: 10.5376/jmr.2019.09.0001

Received: 21 Sep., 2018

Accepted: 29 Oct., 2018

Published: 29 Mar., 2019

Copyright $(9) 219$ Simon-Oke and Akeju, This is an open access article published under the terms of the Creative Commons Attribution License, which permits unrestricted use, distribution, and reproduction in any medium, provided the original work is properly cited.

Preferred citation for this article:

Simon-Oke I.A., and Akeju A.V. 2019, Laboratory evaluation of extract from peels and seeds of some Citrus species against Anopheles mosquitoes (Diptera: Culicidae), Journal of Mosquito Research, 9(1): 1-8 (doi: 10.5376/jmr.2019.09.0001)

\begin{abstract}
Mosquitoes are the most important group of insects known for their public health importance. Efforts to eradicate this disease involve elimination of the vector with natural base insecticides which are safer when compared to synthetic insecticides which are harmful to human. Toxicity effect of extracts from peels and seeds of Citrus sinesis, Citrus aurantifolia and Citrus limonum were evaluated against adult Anopheles mosquitoes at different concentrations and time of exposure; 20, 40 and 60 minutes. The peels and seeds were air dried for 15 days before pulverization. The pulverized peels and seeds were subjected to extraction using soxhlet apparatus and ethanol as solvent. The stock solutions were prepared by adding $0.1 \mathrm{~mL}$ of extract to $9.9 \mathrm{~mL}$ of ethanol to make $1 \%$ concentration. The following different concentrations 5, 10, 15, 20, and 25\% of the extract were prepared as followed; 0.5 , $1.0,1.5,2.0$ and $2.5 \mathrm{~mL}$ of the extract were dissolved in 9.5, 9.0, 8.5, 8.0 and 7.5 $\mathrm{mL}$ of the solvent (Ethanol) respectively with three (3) replicates for each concentration, while $10 \mathrm{~mL}$ of ethanol was used as the control $(0 \%)$. The qualitative and quantitative analyses of the phytochemical constituents were analyzed. The efficacy of the extracted oils was tested on adult female Anopheles mosquitoes. At $25 \%$ concentration, C. aurantifolia peel extract recorded $62.22 \%$ mortality at 60 minutes while the seed extract recorded $50 \%$ mortality at the same concentration and time. The toxicity increased in respect to time of exposure, the toxicity estimation of $\mathrm{LC}_{50}$ was $22.05 \%$ from the extract of $C$. aurantifolia peels and $\mathrm{LC}_{95}$ was $112.27 \%$ for $C$. limonum peels extract after 60 minutes of application. The potency of the Citrus peels and seeds extracts may be as a result of the phytochemical constituents present in them. These results suggest that the Citrus peel and seed extracts have the potential to be used as ideally in eco-friendly approach for the control of the vector control programs.
\end{abstract}

Keywords Anopheles; Citrus sinesis; Citrus aurantifolia; Citrus limonum; Phytochemicals

\section{Background}

Female Anopheles mosquito is one of the most important disease vectors in the insect world, being the vector of Malaria. This vector is of a significant threat to public health because of their ability to transmit parasitic pathogens which afflict millions of people worldwide. Malaria killed over one million people each year, in which the most vulnerable are Children and pregnant women (Adefioye et al., 2007). WHO (2014) reported that about 3.3 billion people are at risk of malaria, out of which 1.2 billion are at high risk.

Approach to combat these diseases largely relies on interruption of the disease transmission cycle by either targeting on the mosquito larvae at breeding sites through spraying stagnant water or by killing/repelling the adult mosquitoes using insecticides (Corbel et al., 2004; Joseph et al., 2004). Synthetic chemical insecticides had been favourable so far due to their quick action and simple application, but this has resulted to insecticide resistance in medically important vectors. Insecticide resistance is increasingly becoming a problem for many vector control programs (Singh et al., 2002; Kumar et al., 2011). The frequent use of chemical insecticides to manage insect has also leads to destabilization of the ecosystem (Kranthi et al., 2001). Number of compounds and materials known today as effective insecticides and pesticides are numerous. Most of these compounds and materials are not without their shortcomings. To alleviate these problems, major emphasis has been on the use of natural plant based products as larvicides and adulticides which can be a safe alternate to synthetic insecticides (Zhu et al., 2008). Citrus seeds and peels contain certain compounds with varied level of bitterness and these compounds have been tested against 
insects and proved to be effective (Effiom et al., 2014). The dried peels of most Citrus fruits have been used in various ways in controlling pests of storage importance by using it in powered form. Recently, attention has been channelled towards the usage of oil extracted from the leaves, peels and seeds of various species of Citrus fruits in controlling vectors of public health importance most especially vector of parasitic diseases. Citrus essential oils are made up mainly of hydrocarbons designated as terpenes and of a smaller amount of sesquiterpenes; these two components serve as carrier for more important class of oxygenated compounds which are usually the bearers of the characteristic odour of the oil in which they are contained (Darjazi, 2014).

The composition varies considerably with the variety of fruit and with the location where the fruit is grown which is based on analyses of juice from different varieties and from different production areas. Terpenoid, one of the major components of Citrus oil has higher level of D-Limonene which serves as a natural insect repellent for Citrus fruits. Direct contact with D-Limonene can act as an organic insecticide. The essential oils extracted from Citrus genus have been proved to contain phytochemicals which includes Saponin, Terpenoid, Cardiac glycoside, Tannin, Alkaloid and Flavonoid. The presence and abundance of these phytoconsistuents depends on varieties of the Citrus species (Kamal et al., 2011; Matthew et al., 2012; Chede, 2013).

\section{Materials and Methods}

\subsection{Study area}

This study was carried out at Environmental Biology and Public Health research laboratory, Federal University of Technology, Akure, Ondo State. The State lies between latitudes $5^{\circ} 45^{\prime}$ and $7^{\circ} 52^{\prime} \mathrm{N}$ and longitudes $4^{\circ} 20^{\prime}$ and $6^{\circ} 05^{\prime} \mathrm{E}$. Its land area is about 15,500 square kilometers.

\subsection{Source of Citrus fruits and their classification}

Freshly harvested species of Citrus fruits (Citrus sinensis, Citrus limonum and Citrus aurantifolica) were brought from local market in Ogbese, Ondo State, Nigeria. The Citrus fruits were brought to the Public Health Research Laboratory, Federal University of Technology Akure, Ondo State.

\subsection{Preparation of extracts}

Freshly harvested oranges were washed with distilled water before peeling. The peels of the oranges were removed by using blade. The seeds of each Citrus fruits were separated manually. The fresh orange peels and seeds of Citrus fruits were air dried separately at room temperature $\left(28 \pm 3^{\circ} \mathrm{C}\right)$ for $15-17$ days. The powdered materials were obtained by grinding the dry peels and seeds into a fine powdered separately using commercial electrical blender. The grounded material was loaded into soxhlet apparatus for solvent extraction of oil by steam distillation method using ethanol as solvent. One and half litres $(1 / 2 \mathrm{~L})$ of ethanol was used sequentially with $500 \mathrm{~g}$ of powered Citrus materials and was subjected to extraction using soxhlet apparatus (Vogel, 1978).

\subsection{Determination of phytochemical active constituents}

Qualitative and Quantitative Phytochemical screening was carried out in Biochemistry Postgraduate Research Laboratory, Federal University of Technology, Akure using established protocols as described by (Sofowora, 1993; Harbone and Harbone, 1998). A stock solution of the extracts with a concentration of $1 \mathrm{mg} / \mathrm{mL}$ was prepared and used for the screening.

\subsection{Source and collection of Anopheles mosquitoes}

Eggs of Female Anopheles mosquitoes were collected from a slow flowing stream and allowed to hatch in the container used for collection in the laboratory. The larvae were reared in the laboratory to 4th instar stage by feeding them with baker yeast and dog biscuits before the emergence of the adults. The pupal stages were transferred into a rearing cage where the young mosquitoes emerged. The adults were provided with $10 \%$ sucrose solution.

\subsection{Identification of adult Anopheles mosquitoes}

The Anopheles Mosquitoes were identified using identifying keys by William (2013). 


\subsection{Preparation of stock solution}

The stock solutions were prepared by adding $0.1 \mathrm{~mL}$ of extract to $9.9 \mathrm{~mL}$ of ethanol to make $1 \%$ concentration. The following different concentrations viz 5, 10,15, 20, and $25 \%$ concentrations of the extract were prepared as followed; $0.5,1.0,1.5,2.0$ and $2.5 \mathrm{~mL}$ of the extract were dissolved in 9.5, 9.0, 8.5, 8.0 and $7.5 \mathrm{~mL}$ of the solvent (Ethanol) respectively with three (3) replicates for each concentration, while $10 \mathrm{~mL}$ of ethanol was used as the control $(0 \%)$.

\subsection{Application of extracts}

Three boxes were used as screen cage $(40 \mathrm{~cm} \mathrm{x} 40 \mathrm{~cm} \mathrm{x} 40 \mathrm{~cm})$. The window screen is made up of 0.25 mesh size 8.5 by $8.5 \mathrm{~cm}$. The prepared extract concentrate was sprayed through the window screen by the means of an insecticide sprayer. Mortality count was taken after 20, 40 and 60 minutes of application. Lethal time (LT) was recorded from the average of three replicates (Owino et al., 2014).

\subsection{Analysis of data}

The data was analyzed using one way Analysis of Variance (ANOVA) followed by Duncan's multiple range test (DMRT) to compare and separate the mean mortality at 5\% level of significance. Probit Analysis was used to estimate the toxicity of the extracts.

\section{Results}

\subsection{Phytochemical analysis of extract}

The qualitative phytochemical screening of oil extracted from Citrus fruits peels and seeds are presented on Table 1. The screening shows that Alkaloids and Steroid are absent in all the Citrus peels and seeds, while Tannins, Cardiac glycosides, Saponins, Flavonoids and Terpenoid are present. Table 2 shows the quantitative phytochemical screening of extract from peels and seeds of Citrus fruits. High percentage of saponnis was found in the Citrus fruits peel and seed extracts with $C$. sinesis peels having the highest percentage $(26.38 \%)$. C. aurantifolia peels contained the highest terpernoid (3.23\%) and tannins (0.24\%). Extract of C. limonum peels had $2.72 \%$ of terpernoid, while C. limonum and C. sinesis peels and seeds had the same quantities of tannins $1.85 \%$ and $1.6 \%$ respectively.

Table 1 Qualitative phytochemical analysis of the extracted oil from Peels and Seeds of Citrus fruits

\begin{tabular}{|c|c|c|c|c|c|c|c|}
\hline Citrus fruits & Constitue & & & & & & \\
\hline Species & Alkaloid & Tannins & Cardiac glycosides & Steroid & Saponins & Flavonoid & Terpernoid \\
\hline $\begin{array}{l}\text { C. aurantifolia } \\
\text { Peels }\end{array}$ & - & + & + & - & + & + & + \\
\hline $\begin{array}{l}\text { C. sinensis } \\
\text { Peels }\end{array}$ & - & + & + & - & + & + & + \\
\hline $\begin{array}{l}\text { C. limonum } \\
\text { Peels }\end{array}$ & - & + & + & - & + & + & + \\
\hline $\begin{array}{l}\text { C. aurantifolia } \\
\text { Seeds }\end{array}$ & - & + & + & - & + & + & + \\
\hline $\begin{array}{l}\text { C. sinensis } \\
\text { Seeds }\end{array}$ & - & + & + & - & + & + & + \\
\hline $\begin{array}{l}\text { C. limonum } \\
\text { Seeds }\end{array}$ & - & + & + & - & + & + & + \\
\hline
\end{tabular}

Note: + present, - absent

\subsection{Insecticidal effect of extract from Citrus fruits peel and seed on mortality of Anopheles mosquitoes}

Table 3 shows the insecticidal effect of Citrus peel extracts on adult Anopheles mosquitoes at different concentrations and periods of exposure, the percentage mortality of the mosquitoes varied with the period of exposure, with extracts from peels of $C$. aurantifolia at $25 \%$ concentration had the highest mortality $(62.22 \%), C$. limonum $(55.55 \%)$ and C. sinesis $(41.11 \%)$ respectively at 60 minutes of application. However, there was a significant difference $(\mathrm{p}<0.05)$ in the mortality rate recorded. 
Journal of Mosquito Research 2019, Vol.9, No.1, 1-8

http://jmr.emtoscipublisher.com

Table 2 Quantitative phytochemical analysis of the extracted oil from Peels and Seeds of Citrus fruits

\begin{tabular}{|c|c|c|c|c|c|}
\hline \multirow{2}{*}{$\begin{array}{l}\text { Citrus fruits } \\
\text { Species }\end{array}$} & \multicolumn{5}{|c|}{ Compound composition (\%) } \\
\hline & Tannins & Cardiac glycosides & Saponins & Flavonoid & Terpernoid \\
\hline C. aurantifolia & 0.2350 & 0.1045 & 19.909 & 11.5939 & 3.2287 \\
\hline \multicolumn{6}{|l|}{ Peels } \\
\hline C. sinensis & 0.1850 & 0.7684 & 26.3812 & 0.7671 & 1.8471 \\
\hline \multicolumn{6}{|l|}{ Peels } \\
\hline C. limonum & 0.1849 & 0.4389 & 12.7909 & 1.1627 & 1.9718 \\
\hline \multicolumn{6}{|l|}{ Peels } \\
\hline C. aurantifolia & 0.1633 & 0.0562 & 8.8172 & 0.4327 & 1.4711 \\
\hline \multicolumn{6}{|l|}{ Seeds } \\
\hline C. sinensis & 0.1601 & 0.5573 & 9.0371 & 0.0892 & 1.0230 \\
\hline \multicolumn{6}{|l|}{ Seeds } \\
\hline C. limonum & 0.1627 & 0.2190 & 9.3111 & 0.2137 & 1.4018 \\
\hline Seeds & & & & & \\
\hline
\end{tabular}

Table 3 Mortality of adult Anopheles mosquitoes on application of Citrus Peel extracts

\begin{tabular}{|c|c|c|c|c|}
\hline \multirow{2}{*}{$\begin{array}{l}\text { Citrus } \text { Fruits } \\
\text { Species }\end{array}$} & \multicolumn{4}{|c|}{$\%$ Mortality $($ Mean \pm S.D $)$} \\
\hline & Conc. $(\%)$ & 20 mins & 40 mins & 60 mins \\
\hline C. limonum & 5 & $1.11 \pm 1.92^{\mathrm{ab}}$ & $4.44 \pm 1.93^{\mathrm{ab}}$ & $7.78 \pm 1.92^{\mathrm{ab}}$ \\
\hline \multirow[t]{5}{*}{ Peel } & 10 & $3.33 \pm 3.34^{\mathrm{ab}}$ & $8.89 \pm 1.92^{\mathrm{bc}}$ & $11.11 \pm 1.92^{\mathrm{abc}}$ \\
\hline & 15 & $11.11 \pm 1.92^{\mathrm{c}}$ & $13.33 \pm 3.34^{\mathrm{cd}}$ & $16.67 \pm 0.00^{\mathrm{bc}}$ \\
\hline & 20 & $15.55 \pm 3.85^{\mathrm{c}}$ & $17.78 \pm 3.85^{\mathrm{de}}$ & $35.56 \pm 16.44^{\mathrm{d}}$ \\
\hline & 25 & $22.22 \pm 5.09^{\mathrm{d}}$ & $29.99 \pm 5.77^{\mathrm{gh}}$ & $55.55 \pm 6.94^{\mathrm{e}}$ \\
\hline & Control & $0.00 \pm 0.00^{\mathrm{a}}$ & $0.00 \pm 0.00^{\mathrm{a}}$ & $0.00 \pm 0.00^{\mathrm{a}}$ \\
\hline C. aurantifolia & 5 & $5.56 \pm 1.92^{\mathrm{b}}$ & $17.78 \pm 5.09^{\mathrm{de}}$ & $34.45 \pm 10.72^{\mathrm{d}}$ \\
\hline \multirow[t]{5}{*}{ Peel } & 10 & $12.22 \pm 1.92^{\mathrm{c}}$ & $27.78 \pm 8.39^{\mathrm{fg}}$ & $34.45 \pm 1.93^{\mathrm{d}}$ \\
\hline & 15 & $23.33 \pm 3.33^{\mathrm{d}}$ & $35.56 \pm 1.93^{\mathrm{hi}}$ & $36.67 \pm 3.34^{\mathrm{d}}$ \\
\hline & 20 & $24.44 \pm 1.92^{\mathrm{d}}$ & $36.67 \pm 3.34^{\mathrm{hi}}$ & $42.22 \pm 6.94^{\mathrm{d}}$ \\
\hline & 25 & $25.56 \pm 1.92^{\mathrm{d}}$ & $40.00 \pm 3.34^{\mathrm{i}}$ & $62.22 \pm 10.18^{\mathrm{e}}$ \\
\hline & Control & $0.00 \pm 0.00^{\mathrm{a}}$ & $0.00 \pm 0.00^{\mathrm{a}}$ & $0.00 \pm 0.00^{\mathrm{a}}$ \\
\hline C. sinesis & 5 & $0.00 \pm 0.00^{\mathrm{a}}$ & $8.89 \pm 1.92^{\mathrm{bc}}$ & $12.22 \pm 1.92^{\mathrm{bc}}$ \\
\hline \multirow[t]{5}{*}{ Peel } & 10 & $11.11 \pm 1.92^{\mathrm{c}}$ & $12.22 \pm 1.92^{\mathrm{cd}}$ & $18.89 \pm 1.92^{\mathrm{bc}}$ \\
\hline & 15 & $11.11 \pm 1.92^{\mathrm{c}}$ & $15.56 \pm 5.09^{\mathrm{cd}}$ & $21.11 \pm 3.85^{\mathrm{c}}$ \\
\hline & 20 & $14.45 \pm 3.85^{\mathrm{c}}$ & $21.11 \pm 1.92^{\mathrm{ef}}$ & $36.67 \pm 3.33^{\mathrm{d}}$ \\
\hline & 25 & $15.55 \pm 3.85^{\mathrm{c}}$ & $26.67 \pm 3.34^{\mathrm{fg}}$ & $41.11 \pm 8.39^{\mathrm{d}}$ \\
\hline & Control & $0.00 \pm 0.00^{\mathrm{a}}$ & $0.00 \pm 0.00^{\mathrm{a}}$ & $0.00 \pm 0.00^{\mathrm{a}}$ \\
\hline
\end{tabular}

Note: Means followed by the same letter in column are not significantly different $(\mathrm{p}>0.05)$ from one another using ANOVA followed by Duncan's New Multiple Range Test (DNMRT)

Table 4 shows the insecticidal effect of the seed extracts, at $25 \%$ concentration for 60 minutes, the highest mortality of $51.11 \%$ was recorded in C. aurantifolia seed extracts while the lowest mortality of $38.88 \%$ was recorded in $C$. sinesis extracts at the same time.

\subsection{Toxicity effect of Citrus extracts against adult Anopheles mosquitoes at $\mathbf{L}_{50}$}

At 20 minutes of $\mathrm{L}_{50}$, C. limonum seed extract had the highest toxicity 96.10 while the peels recorded the least toxicity of 43.04. At 60 minutes of $\mathrm{L}_{50}, C$. sinensis peel extracts recorded the highest mortality of 39.56 with the least of 22.05 in C. aurantifolia peel extracts (Table 5). 
Journal of Mosquito Research 2019, Vol.9, No.1, 1-8

http://jmr.emtoscipublisher.com

Table 4 Mortality of adult Anopheles mosquitoes on application of Citrus Seed extract

\begin{tabular}{|c|c|c|c|c|}
\hline \multirow{2}{*}{$\frac{\text { Citrus } \text { Fruits }}{\text { Species }}$} & \multicolumn{4}{|c|}{$\%$ Mortality $($ Mean \pm S.D) } \\
\hline & Conc. $(\%)$ & 20 mins & 40 mins & 60 mins \\
\hline C. limonum & 5 & $4.45 \pm 3.85^{\mathrm{ab}}$ & $14.44 \pm 1.93^{b c d}$ & $21.11 \pm 1.92^{\text {de }}$ \\
\hline \multirow[t]{5}{*}{ Seed } & 10 & $12.22 \pm 1.92^{\mathrm{cd}}$ & $16.67 \pm 3.33^{\text {cde }}$ & $32.22 \pm 1.92^{\mathrm{fg}}$ \\
\hline & 15 & $17.78 \pm 3.85^{\mathrm{de}}$ & $25.56 \pm 1.93^{\mathrm{fg}}$ & $33.33 \pm 3.34^{\mathrm{ef}}$ \\
\hline & 20 & $18.89 \pm 1.92^{\mathrm{de}}$ & $31.11 \pm 1.92^{\mathrm{gh}}$ & $46.47 \pm 3.34^{\mathrm{ij}}$ \\
\hline & 25 & $21.11 \pm 1.92^{\mathrm{e}}$ & $33.33 \pm 3.34^{\mathrm{h}}$ & $50.00 \pm 6.67^{j}$ \\
\hline & Control & $0.00 \pm 0.00^{\mathrm{a}}$ & $0.00 \pm 0.00^{\mathrm{a}}$ & $0.00 \pm 0.00^{\mathrm{a}}$ \\
\hline C. aurantifolia & 5 & $4.44 \pm 1.93^{\mathrm{ab}}$ & $13.33 \pm 3.34^{\mathrm{bcd}}$ & $15.56 \pm 1.93^{b c}$ \\
\hline \multirow[t]{5}{*}{ Seed } & 10 & $10.00 \pm 5.77^{\mathrm{bc}}$ & $17.78 \pm 1.92^{\text {cde }}$ & $34.44 \pm 1.93^{\text {ef }}$ \\
\hline & 15 & $12.22 \pm 5.09^{\mathrm{cd}}$ & $21.11 \pm 3.85^{\text {ef }}$ & $37.78 \pm 5.09^{\text {fh }}$ \\
\hline & 20 & $20.00 \pm 3.33^{\mathrm{e}}$ & $31.11 \pm 3.85^{\mathrm{gh}}$ & $41.11 \pm 6.94^{\mathrm{hi}}$ \\
\hline & 25 & $23.33 \pm 3.34^{\mathrm{e}}$ & $32.22 \pm 1.92^{\mathrm{h}}$ & $51.11 \pm 3.80^{\mathrm{j}}$ \\
\hline & Control & $0.00 \pm 0.00^{\mathrm{a}}$ & $0.00 \pm 0.00^{\mathrm{a}}$ & $0.00 \pm 0.00^{\mathrm{a}}$ \\
\hline C. sinesis & 5 & $4.44 \pm 5.05^{\mathrm{ab}}$ & $10.00 \pm 5.77^{\mathrm{b}}$ & $10.00 \pm 5.77^{b}$ \\
\hline \multirow[t]{5}{*}{ Seed } & 10 & $10.00 \pm 0.00^{\mathrm{bc}}$ & $12.22 \pm 3.85^{\mathrm{bc}}$ & $24.44 \pm 1.93^{\mathrm{de}}$ \\
\hline & 15 & $11.11 \pm 5.09^{\mathrm{bc}}$ & $18.89 \pm 3.85^{\mathrm{de}}$ & $28.89 \pm 1.92^{\mathrm{ef}}$ \\
\hline & 20 & $18.89 \pm 1.92^{\mathrm{de}}$ & $28.89 \pm 5.09^{\mathrm{gh}}$ & $32.22 \pm 1.92^{\mathrm{fg}}$ \\
\hline & 25 & $18.89 \pm 1.92^{\mathrm{de}}$ & $31.11 \pm 1.92^{\mathrm{gh}}$ & $38.89 \pm 3.85^{\text {gh }}$ \\
\hline & Control & $0.00 \pm 0.00^{\mathrm{a}}$ & $0.00 \pm 0.00^{\mathrm{a}}$ & $0.00 \pm 0.00^{\mathrm{a}}$ \\
\hline
\end{tabular}

Note: Means followed by the same letter in column are not significantly different $(p>0.05)$ from one another using ANOVA followed by Duncan's New Multiple Range Test (DNMRT)

Table 5 Toxicity effect of Citrus materials extract against Anopheles mosquitoes at $\mathrm{L}_{50}$

\begin{tabular}{llll}
\hline $\mathrm{LC}_{50}(\mathrm{LB}-\mathrm{UB})$ & & & \\
\hline Citrus species & $20 \mathrm{~min}$ & $40 \mathrm{~min}$ & $60 \mathrm{~min}$ \\
\hline C. limonum & 43.04 & 58.66 & 26.44 \\
Peel & $(29.19-269.57)$ & $(32.02-172.29)$ & $(20.83-43.21)$ \\
C. limonum & 96.10 & 64.69 & 26.18 \\
Seed & $(37.19-404.2)$ & $(28.75-548.05)$ & $(16.92-204.29)$ \\
C. aurantifolia & 71.42 & 47.47 & 22.05 \\
Peel & $(32.36-455.7)$ & $(23.35-88.17)$ & $(13.13-15127)$ \\
C. aurantifolia & 74.44 & 73.64 & 27.16 \\
Seed & $(35.28-170.7)$ & $(30.55-823.2)$ & $(17.72-176.01)$ \\
C. sinesis & 77.86 & 97.58 & 39.562 \\
Peel & $(36.21-411.9)$ & $(36.89-416.2)$ & $(23.72-469.29)$ \\
C. sinesis & 92.67 & 73.62 & 37.79 \\
Seed & $(37.88-564.66)$ & $(32.04-757.23)$ & $(23.09-389.34)$ \\
\hline
\end{tabular}

Note: $\mathrm{LC}_{50}=$ Lethal concentration at which $50 \%$ population response; $\mathrm{LB}=$ Lower bound; $\mathrm{UB}=$ Upper bound

The impact of the Citrus extracts at different concentrations after 40 minutes of exposure to the mosquitoes showed different level of toxicity (Table 6). Lower percentage mortality of the mosquitoes was recorded from 5 and $10 \%$ concentrations of the Citrus fruits extracts. At Concentration 15, 20 and 25\%, Citrus species extracts eliminated more than $40 \%$ of the adult mosquitoes. C. aurantifolia peels had the high toxicity of $47.47 \%$ at $\mathrm{LC}_{50}$, while $C$. limonum had estimation of $509 \%$ in eliminating $95 \%\left(\mathrm{LC}_{95}\right)$ sample population. High percentage mortality of $62.22,51.11$ and $50 \%$ is seen to have occurred by the impact from $25 \%$ concentration of $C$. aurantifolia peels, seeds and $C$. limonum seeds respectively. The highest percentage mortality $(62.22 \%)$ of mosquitoes was recorded $25 \%$ concentration of $C$. aurantifolia peels. The toxicity estimation of lethal concentration $50 \%\left(\mathrm{LC}_{50}\right)$ of the sample population was shown from the effect of $C$. aurantifolia peel $\left(\mathrm{LC}_{50}\right.$ of $22.05 \%$ ), which is more toxic than other Citrus fruits used in quick elimination of the $50 \%$ sample population. 
Table 6 Toxicity effect of Citrus materials extract against Anopheles mosquitoes

\begin{tabular}{llll}
\hline $\mathrm{LC}_{95}$ (LB-UB) & & & \\
\hline Citrus species & $20 \mathrm{~min}$ & $40 \mathrm{~min}$ & $60 \mathrm{~min}$ \\
\hline C. limonum & 156.68 & 509 & 112.27 \\
Peel & $(64.74-144.8)$ & $(116.90-350.76)$ & $(59.95-559.43)$ \\
C. limonum & 1899.13 & 2387.07 & 652.26 \\
Seed & $(182.29-2280)$ & $(201.45-4368)$ & $(121.76-5476.13)$ \\
C. aurantifolia & 1430.03 & 2435.4 & 1445.40 \\
Peel & $(171.6-1320)$ & $(193.76-6948)$ & $(147.21-2126)$ \\
C. aurantifolia & 989.14 & 2917.78 & 572.66 \\
Seed & $(147.59-3785)$ & $(215.62-1220.56)$ & $(117-795.95)$ \\
C. sinesis & 686.08 & 2383.8 & 631.95 \\
Peel & $(121.33-515.7)$ & $(201.59-9166)$ & $(129.38-4659.74)$ \\
C. sinesis & 1334 & 1897.8 & 580.88 \\
Seed & $(161.87-3122)$ & $(190.23-1727)$ & $(123.69-3177.38)$ \\
\hline
\end{tabular}

Note: $\mathrm{LC}_{95}=$ Lethal concentration at which $95 \%$ population response; $\mathrm{LB}=$ Lower bound; UB $=$ Upper bound

\section{Discussion}

Plant products had been reported to have different phytoconstituent compounds and these depend on the plant varieties and the time of harvest. These compounds are used by the plant as defense against disease agents. The phytochemical compounds found in Citrus peels and seeds must have been the reason behind the bioactivities of the extracts as previously reported by Effiom et al. (2014). Tannins (Tannoid) are acidic in nature and the acidic reaction is attributed to the presence of phenolics or carboxylic group. They are used as antiseptic and this activity is due to presence of the phenolic group. Tannins were found more in C. aurantifolia peel (0.24\%), C. limonum peel and $C$. sinesis peel contained $0.18 \%$, while all the seed extracts contained $0.16 \%$ of tannin. This agreed with the findings of Okwu et al. (2007). The present of Tannins may be the reason for bitter and astringent taste of Citrus fruits particularly in Lime and Lemons.

Flavonoids are important group of polyphenols, they are aromatic compounds and numerous reports support their use as antioxidants or free radical scavengers. Quercertin, Kaempferol and Quercitin are common flavonoids present in plants and Quercitin is known for ability of relieve hay fever and eczema. All the Citrus species extracts contained Saponins which are extremely poisonous, as they cause heamolysis of blood cells and are known to cause cattle poisoning. They possess a bitter and acrid taste, besides causing irritation to mucous membranes (Kar, 2007). Terpernoid were found in all the extracts. Terpene acts as irritants when applied externally and when consumed internally their action resembles that of gastrointestinal tract irritant. The triterpenes include steroids, sterols, and cardiac glycosides with anti-inflammatory, sedative, insecticidal or cytotoxic activity.

The ethanolic extracts of Citrus fruit peels and seeds revealed their insecticidal potential against adult Anopheles mosquitoes as previously reported by Samta et al. (2013). Kumar et al. (2012) reported the use of hexane and petroleum ether as solvent in extracting plant products against Aedes aegypti and Anopheles stephensis which were found to be effective. Ethanolic extracts from Citrus sinesis peels and Piper guineense (seeds and leaves) has also been find to be effective as reported by Ihemanma et al. (2014).

Of the different concentrations, 25\% concentration recorded the highest mortality rate at lethal time 60 (LT 60 ). This result is similar to the work reported by Hazrat et al. (2012). Extracts from the seeds of $C$. limonum and $C$. aurantifolia showed higher mortality rate on the vectors $(50 \%)$ at $\mathrm{LT}_{60}$. However, the effectiveness of all the seeds varied at $\mathrm{LT}_{20}, \mathrm{LT}_{40}$ and $\mathrm{LT}_{60}$ respectively.

All the extracts used showed different levels of potency against the adult Anopheles mosquitoes but the most effective peel extract was from Citrus aurantifolia $(62.22 \%)$ at 25\% concentration after 60 minutes of application. This corroborates the work of Effiom et al. (2014). Jantan et al. (2011) who reported that Citrus limonum contain abundant terpene (D-limonene) which is known to have natural insecticide repellent. 
Percentage mortality recorded from all the seed extracts at $\mathrm{LT}_{20}$ were the same, the lethal effect of $C$. aurantifolia and $C$. limonum seeds gave $50 \%$ mortality, which is similar to the result of adulticidal activities of Citrus seeds Oil reported by Faisal et al. (2010). C. aurantifolia peels and seeds have been identified to contain $7 \%$ typical volatile essential oil, where the main components are limonene, $\beta$-pinene and fenchone. The major component of $C$. aurantifolia oil is limonene which has been described by Asgar (2011) to have insecticidal activities. Limonene was also identified as organic insecticide (Koul et al., 2008).

Ezeonu et al. (2001) reported that the extracts from Citrus aurantifolia and Citrus sinesis peels had better insecticidal activity after 60 minutes of used as indoor spray insecticide, with $C$. sinesis having greater potency on cockroach. However, this did not correlate with the result of this work, where $C$. sinesis showed low efficacy against the vectors. This may be due to the different vectors involved in both research works. Adulticidal activities of extracts from Citrus reticulata and Citrus sinesis (peels and seeds) were also reported by Muhammad et al. (2013). The potential ability of all the Citrus extracts may be due to their phytochemical properties which are secondary metabolites and may have interfered with the insect nervous system.

\section{Authors' contributions}

This work was carried out in collaboration between both authors. Authors IA and AV Designed the study, performed the statistical analysis, wrote the protocol and the first draft of the manuscript. Both authors analyzed the study and literature searches. Both authors read and approved the final manuscript.

\section{Reference}

Adefioye O.A., Adeyeba O.A., Hassan W.O., and Oyerinde O.A., 2007, Prevalence of Malaria Parasite Infection among Pregnant Women in Osogbo, Southwest, Nigeria, American Eurasian Journal of Scientific Research, 2(1): 43-45

Asgar E., 2011, Plant Essential Oils as Source of Natural Insecticide Agent, International Journal of Biological Chemistry, 5: 266-290 https://doi.org/10.3923/ijbc.2011.266.290

Chede P.S., 2013, Phytochemical analysis of Citrus sinensis peel, International Journal of Pharmacology and Biological Sciences, 4(1): 339-343

Corbel V., Duchon S., Zainm M., and Hougand J.M., 2004, Dinotefuran: A potential neonicotinoid insecticide against resistant mosquitoes, Journal of Medical Entomology, 41: 712-717 https://doi.org/10.1603/0022-2585-41.4.712 PMid: 15311465

Darjazi B.B., 2014, The effect of Seasonal Variation on Sour Orange (Citrus aurantifolia) leaf components, International Journal of Agriculture and Biosciences, 3(4): 161-165

Effiom O.E., Avoaja D.A., Ohaeri C.C., and Rwang P.G., 2014, Laboratory Assessment of Bio-efficacies of Phytochemical Extracts from Peels, Pulp and Seeds of Citrus Fruit Species against Anopheles gambiae and Anopheles funestus, Journal of Parasitology, 35(1-2): 123-132

Ezeonu F.C., Chidume G.I., and Udedi S.C., 2001, Insecticidal properties of volatile extracts of orange peels, Bioresource Technology, 76(3): 273-274 https://doi.org/10.1016/S0960-8524(00)00120-6

Faisal H., Waseem A., Anjum S., and Muhammad A.K., 2010, Adulticial Action of Ten Citrus Oil Against Aedes albopictus (Diptera: Culicidae), Pakistain Journal of Agricultural Science, 47(3): 241-244

Harbone J.B., and Harbone A.J., 1998, Phytochemical Methods, a guide to modern techniques of plant analysis, $3^{\text {rd }}$ Edition, Published by Chapman and Hall Int., Edition New York

Hazrat B., Waseem A., Hafiz A.A., Soaib A.H., and Imtinan A.K., 2012, Toxicity of Selected Indigenous Plant Extracts against Aedes albopictus (Diptera: Culicidae): A Potential Dengue Vector in Dengue Positive Areas, Pakistan Journal of Zoology, 44(2): 371-375

Ihemanma C.A., Adindu R.U., Kalu M.K., and Kalu E.J., 2014, Laboratory Evaluation of Ethanolic Extracts of Citrus sinesis Peels and Piper guineenes (Seeds and Leaves) on Mosquitoes Larvae, Journal of Environment and Human, 1: 1

Jantan I., Ahmad A.S., Ahmad A.R., Ali N.A.M., and Ayop N., 2011, Chemical Composition of Some Citrus Oil from Malaysia, Journal of Essential Oil Research, 8(6): 627-632 https://doi.org/10.1080/10412905.1996.9701030

Joseph C.C., Ndoile M.M., Malima R.C., and Nkuniya M.H.M., 2004, Larvicidal and mosquitocidal extracts, a coumarin, isoflavonoids and pterocarpans from Neorautanenia mitis, Trans. R. Soc. Tropical Medicine Hygiene, 98: 451-455 https://doi.org/10.1016/i.trstmh.2003.10.008 PMid: 15186932

Kamal G.M., Anwar F., Hussain A.I., Sarri N., and Ashraf M.Y., 2011, Yield and chemical composition of Citrus essential oils as affected by drying pretreatment of peels, International Food Research Journal, 18(4): 1275-1282

Kar A., 2007, Pharmaocgnosy and Pharmacobiotechnology (Revised-Expanded Second Edition), New Age International Limted Publishres New Delhi, pp.332-600

Koul O., Suresh W., and Dhaliwal G.S., 2008, Essential oil as green pesticides; Potential and constraints, Biopesticides International, 4(1): 63-84 


\section{Journal of Mosquito Research 2019, Vol.9, No.1, 1-8}

http://jmr.emtoscipublisher.com

Kranthi K.R., Jadhav D., Wanjari R., and Russell D., 2001, Pyrethroid resistance and mechanisms of resistance in field strains of Helicoverpa armigera (Lepidoptera: Noctuidae), Journal of Economy Entomology, 94: 253-263 https://doi.org/10.1603/0022-0493-94.1.253

PMid: 11233122

Kumar S., and Pillai M.K.K., 2011, Correlation between the reproductive potential and the pyrethroid resistance in an Indian strain of filarial vector, Culex quinquefasciatus Say (Diptera: Culicidae), Bulletin of Entomology Resources, 101: 25-31 https://doi.org/10.1017/S0007485310000131

PMid:20569518

Kumar S., Warikoo R., Mishra M., Anubha S., and Wahab N., 2012, Larvicidel Efficacy of Citrus limetta Peel Extracts against Indian Strains of Anopheles stephensi and Aedes aegypti L., Parasitology Research, 111(1): 173-178

https://doi.org/10.1007/s00436-011-2814-5 PMid:22231268

Matthew B., Jatawa S.K., and Tiwaari A., 2012, Phytochemical Analysis of C. limonum Pulp and Peel, International Journal of Pharmacy and Pharmaceutical Sciences, 4(2): 269-371

Muhammad S., Dilbar H., Rahat H.R., Hafiz M., Ghulam G., and Muneer A., 2013, Insecticidal activities of two Citrus oils against Tribolium Castaneum (Herbst), American Journal of Research Communication, 1(6): 67-74

Okwu D.E., Awurum A.N., and Okoronkwo J.I., 2007, Phytochemical Composition and In Vitro Antifungi Activity Screening of Extracts from Citrus Plants against Fusarium Oxysporum of Okra Plant (Hibiscus esculentus), African Crop Science Conference Proceeding, 8: 1755-1758

Owino J.O., Ahmed H., and Mary N., 2014, Bio-Assay Guided Fractionation of Anti-mosquito Limonoids from Turraea abyssinica and Turraea cornucopia, Journal Biofertilizer and Biopesticides, 5(1): 142-146

Samta Z., Muhammad S., Abdul R., Asrar M., Khalid M., and Zulqarnain H., 2013, Comparative Bioefficacy of Different Citrus Peel Extracts as Grain Protectant against Callosobruchus chinensis, Trogoderma granarium and Tribolium castaneum, World Applied Sciences Journal, 21(12): 1760-1769

Singh O.P., Raghavendra K., Nanda N., Mittal P.K., and Subbarao S.K., 2002, Pyrethroid resistance in Anopheles culicifacies in Surat district, Gujarat, west India, Current Science, 82: 547-550

Sofowora A., 1993, Medicinal Plants and Traditional Medicine in Africa, 2nd edition, Spectrum Books Limited, Ibadan, Nigeria, pp.134-156

Vogel A.I., 1978, In: Text Book of Practical Organic Chemistry, The English language Book Society and Longman, London, pp.1368

WHO, 2014, World Malaria report

William W.S., 2013, Identification Guide to Adult Mosquitoes of Saginaw County, Mosquito Abatement Commission (Book)

Zhu J., Zeng X., O’Neal M., Schultz G., Tucker B., Coats J., Bartholomay L., and Xue R.D., 2008, Mosquito larvicidal activity of botanical-based mosquito repellents, Journal of American Mosquitoes Control Association, 24: 161-168 https://doi.org/10.2987/8756-971X(2008)24[161:MLAOBM]2.0.CO;2 